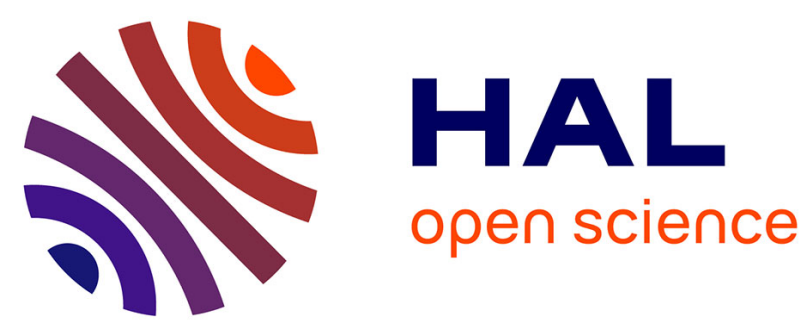

\title{
MÖSSBAUER EXPERIMENTS WITH COULOMB-EXCITED 57Fe AFTER RECOIL IMPLANTATION INTO fcc-LATTICES
}

D. Seyboth, U. Volland, B. Brzoska, J. Baumann, F. Sontheimer, K. Wimmer

\section{- To cite this version:}

D. Seyboth, U. Volland, B. Brzoska, J. Baumann, F. Sontheimer, et al.. MÖSSBAUER EXPERIMENTS WITH COULOMB-EXCITED 57Fe AFTER RECOIL IMPLANTATION INTO fcc-LATTICES. Journal de Physique Colloques, 1974, 35 (C6), pp.C6-305-C6-308. 10.1051/jphyscol:1974648 . jpa-00215805

\section{HAL Id: jpa-00215805 https://hal.science/jpa-00215805}

Submitted on 1 Jan 1974

HAL is a multi-disciplinary open access archive for the deposit and dissemination of scientific research documents, whether they are published or not. The documents may come from teaching and research institutions in France or abroad, or from public or private research centers.
L'archive ouverte pluridisciplinaire HAL, est destinée au dépôt et à la diffusion de documents scientifiques de niveau recherche, publiés ou non, émanant des établissements d'enseignement et de recherche français ou étrangers, des laboratoires publics ou privés. 


\title{
MÖSSBAUER EXPERIMENTS WITH COULOMB-EXCITED ${ }^{57} \mathrm{Fe}$ AFTER RECOIL IMPLANTATION INTO fcc-LATTICES
}

\author{
D. SEYBOTH, U. VOLLAND, B. BRZOSKA, J. BAUMANN \\ F. SONTHEIMER and $\mathrm{K}$. WIMMER
}

Physikal. Institut der Universität Erlangen-Nürnberg (German Federal Republic)

\begin{abstract}
Résumé. - Nous avons étudié à température ambiante l'effet Mössbauer de ${ }^{57} \mathrm{Fe}$ excité par excitation coulombienne et implanté sous vide dans des matrices de cuivre, d'argent et d'aluminium. Les paramètres Mössbauer permettent de conclure que les atomes de recul substituent en moins de $10^{-7} \mathrm{~s}$ des sites normaux dans les réseaux de $\mathrm{Cu}$ et $\mathrm{Ag}$. Un faible élargissement de la raie de résonance de Fe dans $\mathrm{Ag}$ peut provenir de quelque dommage dû au rayonnement. Dans le cas de ${ }^{57 \mathrm{Fe}}$ implanté dans $\mathrm{Al}$ nous pensons qu'une proportion élevée des noyaux de recul excités arrivent au repos dans une position interstitielle, le reste étant stoppé dans des sites de substitution du réseau.

Abstract. - The Mössbauer effect of Coulomb-excited ${ }^{57} \mathrm{Fe}$ implanted through vacuum into copper, silver and aluminum was studied at room temperature. From the derived Mössbauer parameters we conclude that the recoils are substituted into regular lattice sites of $\mathrm{Cu}$ and $\mathrm{Ag}$ within $10^{-7} \mathrm{~s}$. A small line broadening in the case of $\mathrm{Fe}$ in $\mathrm{Ag}$ may reflect some radiation damage. For ${ }^{57 \mathrm{Fe}}$ implanted into $\mathrm{Al}$ we tend to say that a large fraction of the excited recoils comes to rest in a split interstitial configuration while the other implanted impurity atoms are stopped on substitutional lattice sites.
\end{abstract}

1. Introduction. - In solid state physics the standard method to study tadiation damage is to measure changes of integial properties of the solid, due to damages of the lattice after irradiation. The most powerful technique for this purpose are electrical resistivity measurements, which are not very specific for the various kinds of defects present in the sample and rather insensitive to trapping reactions and aggregations. Mössbauer experiments, however, being a microscopic method, are able to give selective informations about the local environment of the Mössbauer atom and about neighbouring defects. Therefore the application of Mössbauer spectroscopy to radiation damage problems is obvious. ${ }^{57} \mathrm{Fe}$ is a suitable microscopic probe, because the linewidth of the $14.4 \mathrm{keV}$ level is small or at least comparable with typical hyperfine interaction energies seen with this nucleus and experiments can be performed up to high temperatures, in order to investigate annealing of radiation damages.

This paper is a report on Mössbauer effect studies of Coulomb-excited ${ }^{57} \mathrm{Fe}$ nuclei implanted into fcc-type metals copper, silver and aluminum. The Mössbauer effect is observed within $10^{-7} \mathrm{~s}$ after excitation of ${ }^{57} \mathrm{Fe}$ and implantation into the host, limited by the nuclear lifetime. Therefore, the Mössbauer spectrum is only sensitive to implantation induced defects, which are formed and do not anneal within that time scale.

2. Coulomb recoil implantation and radiation damage. - Mössbauer experiments after Coulomb excitation have been carried out in several laboratories. A list of references is given in the papers of Sprouse and Kalvius [1] and Obenshain [2]. Exciting the nuclear Mössbauer level by Coulomb excitation, high kinetic energies are transfered to the target nuclei during the collision. A large fraction of the excited Mössbauer atoms can be implanted into a host lattice, where they de-excite emitting a gamma ray. The slowing down mechanism of the implanted atoms can be devided into two characteristic stages [3] : Above a few ten $\mathrm{keV}$ the kinetic energy loss is mainly due to electronic excitation and ionisation of the lattice atoms. Below ten $\mathrm{keV}$ the excitation of lattice vibrations and the displacement of lattice atoms dominate in the stopping process. On the average an energy of about 30 to $50 \mathrm{eV}$ is needed in metals for displacing an atom. A primary displaced atom leaves behind a vacancy and may give rise to further displacements or may come to rest interstitially. Thus the radiation damage consists of at least a few hundred vacancies and interstitials. The defects are in isolated sites or form larger configurations. At temperatures different from zero annealing of the radiation damage has to be taken into account.

A direct implantation, as used earlier with ${ }^{61} \mathrm{Ni}$ [4] and ${ }^{73} \mathrm{Ge}$ [3] [5], is not appropriate in our case for the following reasons :

a) The yield for background radiation, mainly $\mathrm{X}$-rays, is much higher than the production of nuclear gamma radiation by Coulomb excitation, which gives rise to a severe background problem in the case of ${ }^{57} \mathrm{Fe}$. 
b) With the direct implantation method, one has a superposition of two radiation damage processes: There is a radiation damage caused by the slowing down of the recoiling ${ }^{57} \mathrm{Fe}$ nuclei as described above. In addition the exciting beam produces an overall damage of the host matrix. This damage is not correlated with the final position of the individual implanted ${ }^{57} \mathrm{Fe}$ Mössbauer nucleus.

Coulomb fxcitation Mössbauer experiments are a unique tool to study the radiation damage produced during the slowing down process, whereas damages caused by beams of charged particles or neutrons are better studied by irradiation of radioactive Mössbauer sources [6] [7]. In order to avoid the overlap of these two kinds of radiation, we have chosen an implantation method through vacuum, where the exciting beam does not strike the implantation matrix. In our experiment the concentration of implanted impurities in the host lattice remains extremely low, in the order of $10^{-12}$ to $10^{-10}$.

3. Experimental technique. - The experimental arrangement is almost identical to that used by Sprouse and Kalvius [1], and is described in references [8] and [9]. A collimated beam of $25 \mathrm{MeV} \mathrm{O}^{4+}$ ions bombards a thin metallic target $\left(1.9 \mathrm{mg} / \mathrm{cm}^{2}\right)$ of enriched ${ }^{57} \mathrm{Fe}$ and is stopped in a beam stopper. The oxygen ions Coulomb-excite ${ }^{57} \mathrm{Fe}$ target nuclei, mainly the $136 \mathrm{keV}$ level which then populates the $14.4 \mathrm{keV}$ Mössbauer level by gamma emission. With the geometry and target thickness used, a large fraction of the excited ${ }^{57} \mathrm{Fe}$ nuclei recoil through vacuum into the matrix of a catcher foil. Foils of metallic copper, silver and aluminum were used, the thickness was $2.5 \mu \mathrm{m}, 5 \mu \mathrm{m}$ and $3 \mu \mathrm{m}$, respectively. The lifetime of the Mössbauer level being long compared with the flighttime, about $98 \%$ of the nuclei decay in the catcher after being stopped. The transmission of the $14.4 \mathrm{keV}$ gamma rays through a resonant absorber of $0.25 \mathrm{mg} / \mathrm{cm}^{2}$ enriched ${ }^{57} \mathrm{Fe}$ in $\mathrm{Na}_{4} \mathrm{Fe}(\mathrm{CN})_{6} .10 \mathrm{H}_{2} \mathrm{O}$ is measured with a standard Mössbauer spectrometer using a drive system with sinusoidal motion. Both, the implantation foil and the absorber are on room temperature. With a beam current of $250 \mathrm{nA}$ of $\mathrm{O}^{4+}$ ions, the counting rate in a xenon-filled proportional counter is about $35 . \mathrm{s}^{-1}$ of $14.4 \mathrm{keV}$ gamma rays superposed on a counting rate of 50 to $200 \mathrm{~s}^{-1}$ of background counts in the window of the single channel analysator, depending on the focus of the Tandem accelerator. In order to be able to make a background correction for determination of Debye-Waller factors, a gamma ray spectrum is taken simultaneously with the Mössbauer spectrum in a separate multichannel analyser.

4. Experimental results. - The Mössbauer spectra of Coulomb-excited ${ }^{57} \mathrm{Fe}$ recoils implanted into $\mathrm{Cu}, \mathrm{Ag}$ and $\mathrm{Al}$ are shown in figures 1,2 and 3, respectively, and are not background corrected. With the aid of a com-

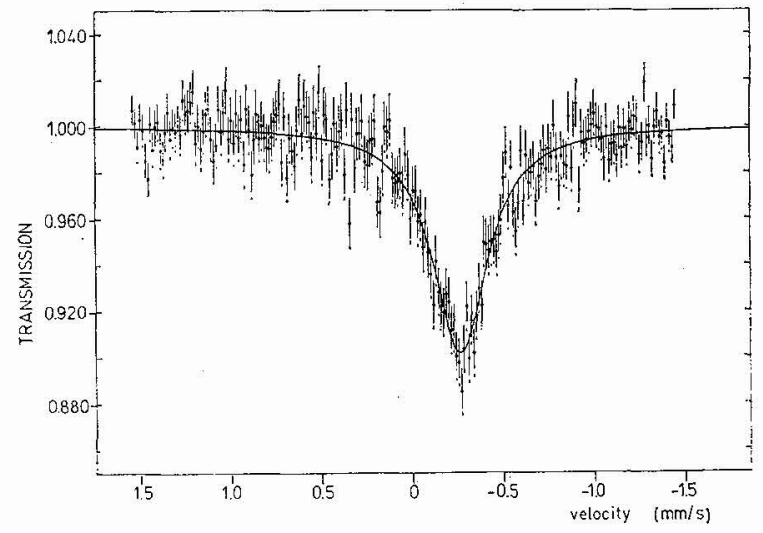

FIG. 1. - Mössbatuer spectrum of 57Fe implanted into copper.

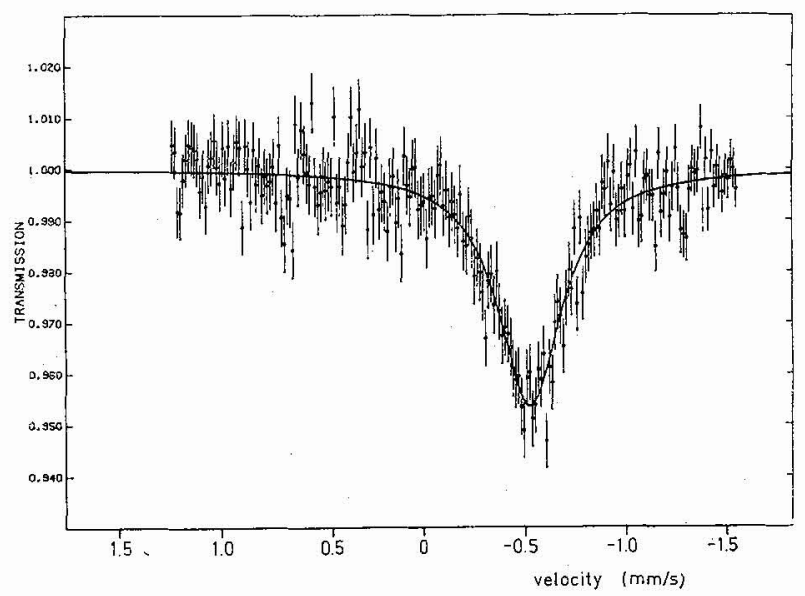

Frg. 2. - Mössbauer spectrum of $57 \mathrm{Fe}$ implanted into silver.

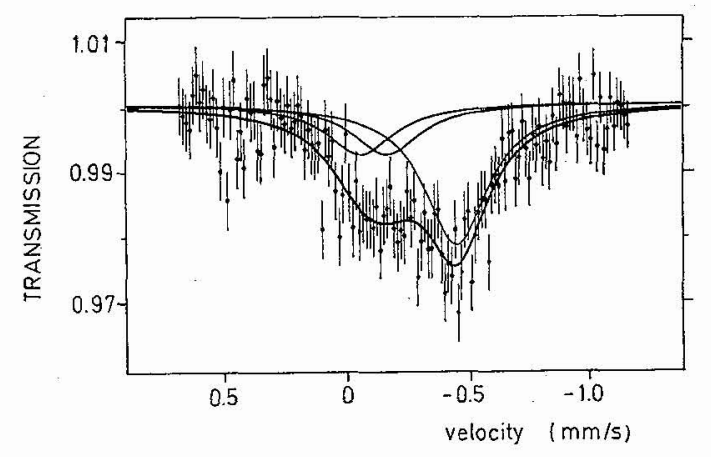

FIG. 3. - Mössbauer spectrum of $57 \mathrm{Fe}$ implanted into aluminum.

puter program all spectra were least-squares fitted with Lorentzian lines. Best fits were obtained for $\mathrm{Cu}$ and $\mathrm{Ag}$ with a single line. The spectrum of ${ }^{57} \mathrm{Fe}$ implanted into $\mathrm{Al}$ consists of a doublet and a single line. In figure 3 the doublet is plotted as two single lines which have been constrained to equal intensities and equal fixed linewidths. The Mössbauer parameters derived from these measurements are listed in table I. The given errors of the parameters are statistical errors. In all cases the line broadening due to the thickness of the 
TABLE I

Parameters measured at $300 \mathrm{~K}$ for ${ }^{57} \mathrm{Fe}$ implanted into copper, silver and aluminum

$\begin{array}{ccccc}\text { Host } & \begin{array}{c}\text { Linewidth } \\ (\mathrm{mm} / \mathrm{s})\end{array} & \begin{array}{c}\text { Shift vs Fe } \\ (\mathrm{mm} / \mathrm{s})\end{array} & \begin{array}{c}\text { Quadrupole } \\ \text { splitting } \\ (\mathrm{mm} / \mathrm{s})\end{array} & \begin{array}{c}\text { Foot- } \\ \text { note }\end{array} \\ - & -\overline{-} & - & - & - \\ \mathrm{Cu} & 0.36 \pm 0.02 & -0.26 \pm 0.03 & & \\ & 0.339 \pm 0.004 & -0.23 \pm 0.03 & & \\ \mathrm{Ag} & 0.39 \pm 0.03 & -0.54 \pm 0.01 & & \\ & 0.32 \pm 0.06 & -0.45 \pm 0.02 & & \\ \mathrm{Al} & 0.33 & -0.11 \pm 0.04 & 0.11 \pm 0.08 & \end{array}$

(1) $57 \mathrm{Co}$ in $\mathrm{Cu}$ source with the same absorber.

(2) Spectrum fitted with a single line and with a doublet. The two lines of the doublet have been constrained to equal intensities and equal fixed linewidths.

absorber has not been corrected. The linewidth of the $\mathrm{Na}_{4} \mathrm{Fe}(\mathrm{CN})_{6} .10 \mathrm{H}_{2} \mathrm{O}$ absorber is $(0.339 \pm 0.004) \mathrm{mm} / \mathrm{s}$ and is purely due to the thickness of the absorber. A ${ }^{57} \mathrm{Co}$ in $\mathrm{Cu}$ source, used for this calibration, gave a linewidth of $0.225 \mathrm{~mm} / \mathrm{s}$ at zero thickness of the absorber, deduced from a series of measurements with thin Armco Iron foils.

The Debye-Waller factors for ${ }^{57} \mathrm{Fe}$ implanted into copper and silver were estimated. For this purpose the recoilless fraction of the ${ }^{57} \mathrm{Co}$ in $\mathrm{Cu}$ source was measured by the black absorber technique. Then the recoilless fractions were obtained from the area ratios of the implantation spectra with the spectrum of ${ }^{57} \mathrm{Co}$ in $\mathrm{Cu}$ source, using the same absorber. A relatively great uncertainty in determining the signal to background ratios makes it impossible to evaluate the Debye-Waller factors with relative errors better than $20 \%$. Within these large errors the recoilless fractions are in agreement with those for ${ }^{57} \mathrm{Co}$ diffused into $\mathrm{Cu}$ and $\mathrm{Ag}$, as given in literature.

5. Discussion. - 5.1 IMPLANTED Fe IN COPPER AND SILVER. - Except for the slightly broadened Mössbauer line in the case of $\mathrm{Fe}$ in $\mathrm{Ag}$ all relevant parameters of both spectra agree with those derived from measurements of dilute solutions of $\mathrm{Fe}$ in $\mathrm{Cu}$ and $\mathrm{Ag} \mathrm{[10].} \mathrm{This} \mathrm{indicates} \mathrm{that} \mathrm{within} \mathrm{the} \mathrm{nuclear} \mathrm{life-}$ time of $10^{-7} \mathrm{~s}$ all ${ }^{57} \mathrm{Fe}$ recoils reach normal lattice sites in the host lattice. Vacancies created in the neighbourhood must anneal within $10^{-7} \mathrm{~s}$. The reason for this may be that for metals with high atomic mass, such as $\mathrm{Cu}$ and $\mathrm{Ag}$, the local defect density produced by the displacement cascades is so high that spontaneous recombination processes occur frequently [11]. Another reason might be that the migration energy of the vacancies is altered, due to the presence of the iron impurity.

For implanted ${ }^{57} \mathrm{Fe}$ atoms into a cubic lattice on substitutional sites with undisturbed vicinities one will expect a single line in the Mössbauer spectrum. Even if the implanted impurity has an atomic size different from that of the host lattice atoms, it should give rise only to cubically symmetric distortions. Therefore the local environment about each site will remain cubic and there will be no quadrupole fields [12]. Thus the Mössbauer spectrum should consist of an unbroadened single line.

We tend to say that in the case of ${ }^{57} \mathrm{Fe}$ implanted into Ag the slightly broadened line is produced by defects at greater distances from the implanted Mössbauer atom.

5.2 Implanted Fe in aluminum. - Recently Vog1 et al. [7] have studied the Mössbauer effect of a dilute ${ }^{57} \mathrm{Co}$ in $\mathrm{Al}$ source after neutron irradiation at low temperatures $(4.6 \mathrm{~K})$. Before irradiation the spectrum shows a single line. Annealing between 35 and $50 \mathrm{~K}$ after irradiation induces an additional quadrupole split line which has an isomer shift and a quadrupole splitting of $-0.09 \mathrm{~mm} / \mathrm{s}$ and $0.09 \mathrm{~mm} / \mathrm{s}$, respectively. During annealing at higher temperatures than $180 \mathrm{~K}$ the intensity of the new line decreases and above $250 \mathrm{~K}$ the spectrum consists again of a single line only. They conclude that a well-defined configuration of a ${ }^{57} \mathrm{Co}$ impurity and an interstitial aluminum atom is formed. This complex should be an interstitial dumbbell configuration in which one cubic site is shared by two atoms. An additional argument for this configuration was recently given by backscattering experiments [13] where $\mathrm{Al}-\mathrm{Mn}$ dumbbells were seen. $\mathrm{Mn}$ and Co have comparable atomic size and thus may have a similar trapping behaviour.

In our case of implanted ${ }^{57} \mathrm{Fe}$ into $\mathrm{Al}$ the derived Mössbauer parameters agree surprisingly well with those measured by Vogl. Thus we are sure that in our experiment the same split interstitial configuration is formed. But we suppose the trapping mechanism being quite different from that one of Vogl. In recoil implantation experiments after Coulomb excitation the obtained Mössbauer spectrum can be only sensitive to radiation induced defects which are formed within the nuclear lifetime, e. g. $10^{-7} \mathrm{~s}$ for ${ }^{57} \mathrm{Fe}$. In this time scale only interstitials are highly mobile whereas vacancies ate practically frozen in at room temperature. It seems rather unprobable that a large fraction of excited ${ }^{57} \mathrm{Fe}$ atoms can trap migrating interstitials and form in this way the split interstitial configuration, before emitting a gamma ray. A possibility to explain our measurement may be the following : A fraction of the implanted impurities comes to rest on substitutional sites and gives rise to the single line of the solid solution phase. The other recoils are stopped interstitionally. There they push a neighbouring aluminum atom out of its regular lattice site forming the same dumbbell configuration as found after neutron irradiation. Our measurements show that this split interstitional configuration is stable at room temperature for at least $10^{-7} \mathrm{~s}$.

Acknowledgment. - Financial support of the Bundesministerium für Forschung und Technologie is gratefully acknowledged. 


\section{C6-308 D. SEYBOTH, U. VOLLAND, B. BRZOSKA, J. BAUMANN, F. SONTHEIMER AND K. WIMMER}

Note added in Proof. - We are aware that our interpretation of the spectrum of $\mathrm{Fe}$ implanted into $\mathrm{Al}$ must be proofed by additional experiments. The agreement of the Mössbauer parameters with those measured after neutron irradiation may be accidental. On the other hand our interpretation is supported by a preliminary determination of the Debye-Waller factor of the implanted ${ }^{57} \mathrm{Fe}$. The areas $a_{\mathrm{d}}$ and $a_{\mathrm{s}}$ under the absorption dips of the doublet and the single line were deduced from the fit. The ratio $a_{\mathrm{d}} / a_{\mathrm{s}}$ is $0.74 \pm 0.22$. The occupation probabilities of both lattice sites after recoil implantation are not known. Therefore, in order to get a relation between the recoilless fractions of both sites, we had measured the Mössbauer transmission of our absorber with a source of known Debye-Waller factor. In the Debye approximation we derive $\Theta_{\mathrm{d}}=(160 \pm 30) \mathrm{K}$ for the dumbbell configuration assuming $\Theta_{\mathrm{s}}=(280 \pm 20) \mathrm{K}$ for the solid solution of $\mathrm{Fe}$ in Al. Again this result is in good agreement with the data given by Vogl. We are planning implantation experiments at higher and lower temperatures to obtain more detailed informations.

\section{References}

[1] Kalyius, G. M., Sprouse, G. D., Mössbauer Effect Methodology, Vol. 4 (Plenum Press, New York) 1968 p. 37.

[2] Obenshain, F. E., Mössbauer Effect Methodology, Vol. 4 (Plenum Press, New York) 1968 p. 61.

[3] ZimmermanN, B. H., Jena, H., Ischenko, G., Kiltan, H. and SEYBoth, D., Phys. Stat. Sol. 27 (1968) 639.

[4] Seyboth, D., Obenshain, F. E. and Czjzek, G., Phys. Rev. Lett. 14 (1965) 954.

[5] Czjzek, G., Ford Jr, J. L. C., Love, J. C., Obenshain, F. E. and WEGENER, H. H. F., Phys. Rev. 174 (1968) 331

[6] Jena, H., Baumann, J., Brzoska, B., Seyboth, D. and SonTHEIMER, F., Jahresbericht, Physikalisches Institut der Universität Erlangen-Nürnberg (1970/71).

[7] Mansel, W., Vogl, G. and Koch, W., Proceedings of the 5th International Conference on Mössbauer Spectroscopy, Bratislava, to be published.
[8] Brzoska, B., Diplomarbeit, Phys. Inst Erlangen (1971).

[9] Brzoska, B., Baumann, J., Jena, H., Sexboth, D. and SONTHEIMER, F., Proceedings of the 5th International Conference on Mössbauer Spectroscopy, Bratislava, to be published.

[10] Kitchens, T. A., Steyert, W. A. and TAYlor, R. D., Phys. Rev. 138A (1965) 467.

[11] Schilling, W., Burger, G., Isebeck, K. and Wenzl, H., Vacancies and Interstitials in Metals (North Holland Amsterdam) 1970 p. 255.

[12] Preston, R. S. and Gerlach, R., Phys. Rev. B 3 (1971) 1519.

[13] Swanson, M. L., Maury, F. and Quenneville, A. F., Phys. Rev. Lett. 31 (1973) 1057. 